SOME OBSERVATIONS ON THE DISINTEGRATION OF. CINDER CONCRETE.

By Grorge BorkowMan.

Received Feb. 8,1912

Cinders, as an aggregate in concrete, are used rather commonly where a light, cheap mixture is desirable; also in fire-proof construction and perhaps in the latter capacity this kind of concrete finds its most important application.

Its efficiency, however, has been the subject of considerable discussion. Various tests have been made, the results of which tend to show the superiority of this material over all other fure-resisting substances. There are also several patented floors involving cinder concrete which have been used successfully. Nevertheless, it has failed in some instances when employed for ordinary purposes, cracking and disintegration taking place. These discordant results are due, no doubt, as Freitag suggests in his "Fire-proofing of Steel Buildings," to the use of cinders of varying quality, but to the writer's knowledge the matter has not been further investigated. A particular case of disintegration, accompanied by a powdery efforescence on the surface of the concrete, was observed by Dr. S. Avery, now Chancellor, but formerly head of the department of chemistry in this University, who prompted some study of the phenomena and also made various help. ful suggestions during the experiments.

Blocks of concrete containing cement, sand and guarter-inch cinders were first prepared, the proportions by weight being $I: 2: 3$, respectively. The cinders were from steam coal and slack and were carefully screened. The cement and sand were of good quality, the latter being sieved through twenty mesh onto thirty.

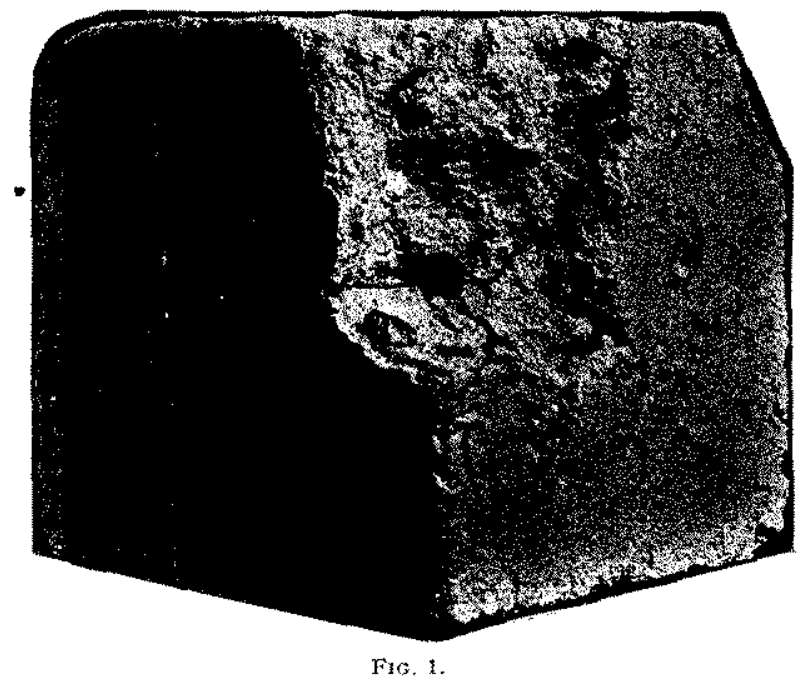

Another lot was then made up using cinders from one-half to one inch in size, the proportions being I : I : $x$. In each case just enough water was used to insure thorough incorporation without running. All the blocks were placed on a glass plate to prevent loss of moisture and covered with a damp cloth for two weeks.
At the end of this period, the specimens having the proportions $x: 3: 3$ showed no change but were somewhat porous and friable, owing to the relatively large bulk of cinders. A little later, however, fine cracks developed, with general disintegration. The others (I : I : I), though compact and hard, also

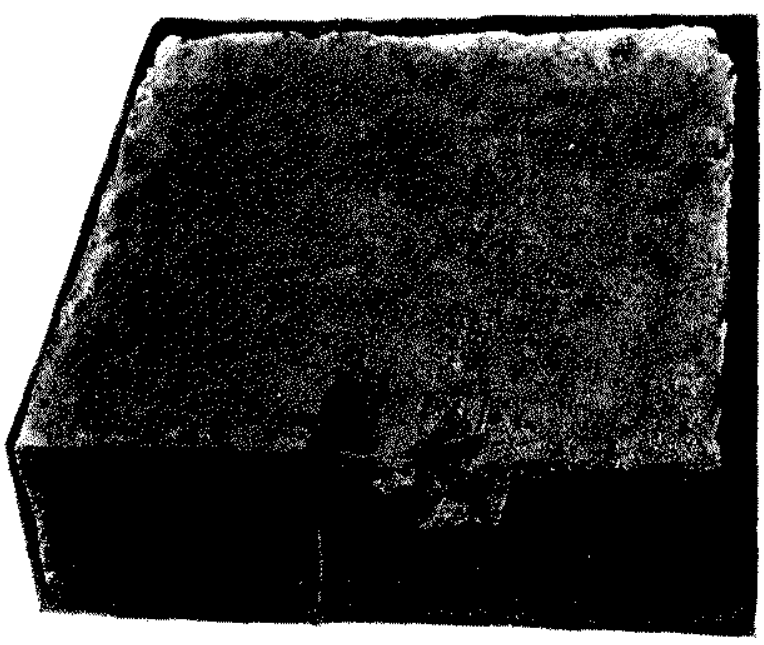

1*IS. 2 .

showed signs of cracking and in a short time the breaks became very pronounced. In each case they radiated from certain points.

These latter specimens were broken open to facilitate examination and in some cases the breaks originated from cinders that showed oxidation of much iron. The accompanying cuts show plainly these nodules and the mode of cracking. The surfaces of the concrete bounding the cracks crumbled easily, indicating more or less general weakening.

The appearance of these oxidized cinders suggested the presence, originally, of much ferrous iron, probably as sulphide. The analysis of the cinder stock showed considerable sulphur as sulphide and sulphate; also iron, though the proportion of ferrous iron could not be determined in material of this sort, with accuracy:

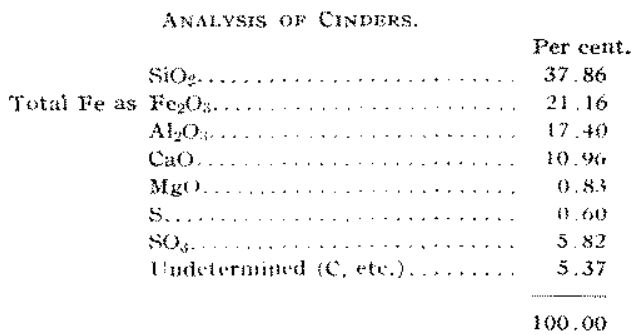

It seemed probable, then, from the foregoing data, that oxidation of iron and sulphur produced internal stress and consequent cracking, aided, no doubt, by the general weakness produced by the diffusion of soluble sulphates. This theory was further strengthened by finding that the efflorescence, found on the surface of the disintegrating concrete before mentioned, was ferrous sulphate.

On this assumption attempts were made to bring about similar results by substituting for cinders artificial iron sulphide, prepared in several ways. 
These experiments, however, were not successful. On breaking open the blocks, the sulphide was found to be unchanged, surrounded by hard, compact cement. Soluble sulphates being absent in the mixture, the blocks had, of course, greater initial strength than those containing cinders and would have withstood considerable stress had there been any. The lack of

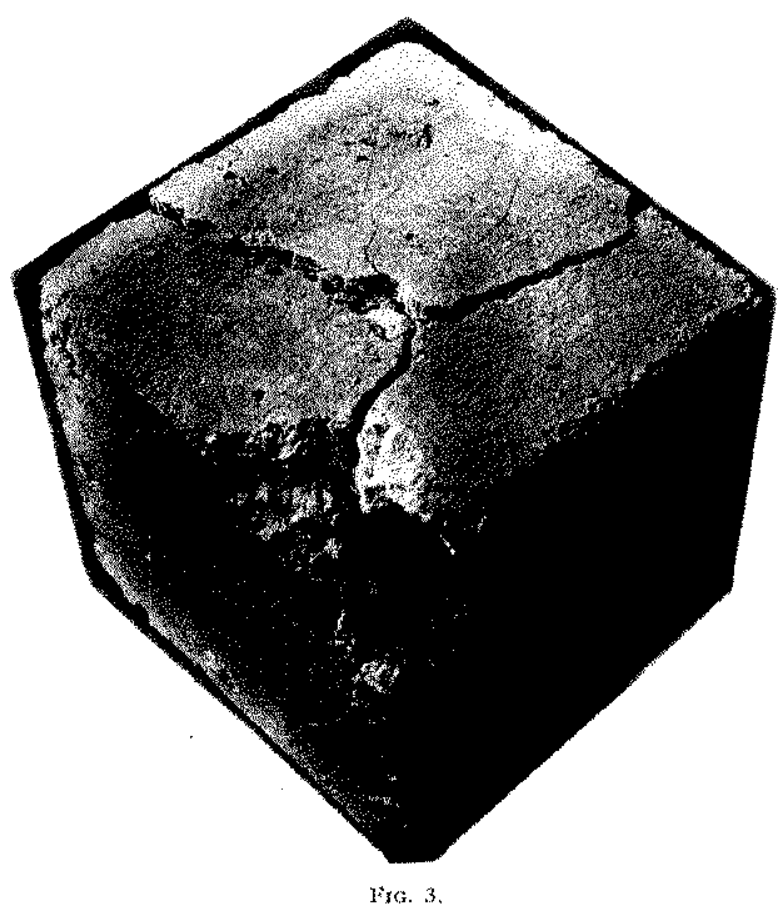

oxidation, though, in these tests, indicated that in the case of the cinders the necessary oxygen must have come from the cinders themselves, since they were equally well protected from the air.

This conclusion drew attention to the fact that about one-third of the cinder stock consisted of a very porous coke. As is well known, this substance will persistently occlude large amounts of oxygen. According to Starr and Lewis, air-dried coke contains absorbed gases in the proportion of about seventenths of a cubic centimeter per gram of coke, two to six per cent. of the gases being oxygen. The oxidation in the concrete was most pronounced in the coke. Moreover, some pieces of the latter were picked from the cinder stock and tested for sulphide sulphur, about one per cent. being found. The nodule from which the cracks radiate in Fig. I proved to be a piece of coke so thoroughly oxidized as to look like a mass of ferric oxide. This was tested and found to contain but a trace of sulphur.

As a final experiment, some of the original stock of cinders were kept exposed to air and moisture until, on washing, they showed the presence of no soluble sulphate. They were then made into a block of concrete similar to those prepared before (I : I : I). Under parallel conditions no disturbance took place, the material retaining perfect stability.

From these tests we may conclude that cinders with much sulphide and sulphate sulphur are likely to give unsatisfactory results, especially if there is much coke or porous material present; also that such material may be improved if allowed to weather, with occasional washing, until the ferrous iron and sulphur have been oxidized and leached out.

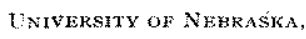

\section{SOME PROBLEMS IN CHEMICAL ENGINEERING PRACTICE.}

THE MANUFACTURE OF CHLOROFORM FROM BLEACHING POWDER AND ETHYL ALCOHOL.

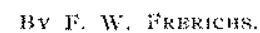

Received lamary 5, 1912.

(Concluded from the $\mathrm{Hay}$ No.)

Experiments Series $l^{t}$, comprising six experiments and representing six days' work in the plant, were made to determinc whether that part of cthyl alomol which is destroyed in the re action can be substituted by methyl alcolol.

Apparatus Fig. 2 (page 350 ) was used, with $1500 \mathrm{cc}$. retort.

The experiments wete made in the same manner as the experiments of Series $\mathrm{l}$, only the larger part of the ethyl alcohol was substituted by methyl alcohol.

I. Materials used: 100 grams bleach, 35 per ecnt.; enough water to make $500 \mathrm{cc}$; $20 \mathrm{cc}$. ethyl alcohol, 94 per cent; $500 \mathrm{cc}$. methyl alcohol, 90 per cent. free of acetone; mixed at $20^{\circ} \mathrm{C}$ and distilled. Products obtained: $₹ .2$ grams chloroform washed, s. G. 1.48:700 cc. diluted mixed alcohols (distillate A)

2. Materials used: 100 grams bleach, 35 per cent.; enough water to make $300 \mathrm{cc}$; $20 \mathrm{cc}$. ethyl alcohol, 94 per cent.; 700 ce. distillate $\mathrm{A}$; mixed at $20^{\circ} \mathrm{C}$. and distilled. Products obtained: 3.7 grams washed chloroform, s. g. $1.48 ; 700 \mathrm{cc}$. diluted mixed alcohols (distillate $B$ ).

3. Materials used: 100 grams bleach, 35 per cent.; enough water to make $300 \mathrm{cc}$; $20 \mathrm{cc}$, ethyl alcohol, 94 per cent.; $700 \mathrm{cc}$. distillate $\mathrm{B}$; mixed at $20^{\circ} \mathrm{C}$. and distilled. Products obtained: 5.2 grams washed chlorolorm, s. g. 1.48; $700 \mathrm{cc}$ diluted mixed alcohols (distillate $\mathrm{C}$.).

4. Materials used: 100 grams bleach, 35 per cent.; enough water to make $300 \mathrm{cc}$; $20 \mathrm{cc}$, ethyl alcohol, 94 per cent.; 700 cc. distillate $\mathrm{C}$ mixed at $20^{\circ} \mathrm{C}$. and distilled. Products obtained: 7.2 grams chloroform washed, s. $8.1 .48 ; 700 \mathrm{cc}$. diluted mixed alcohols (distillate $D$ ).

5. Materials used: 100 grams bleach, 35 per cent.; enough water to make $300 \mathrm{cc} ; 20 \mathrm{cc}$. ethyl alcohol, 94 per cent,; 700 ce. distillate D; mixed at $20^{\circ} \mathrm{C}$. and distilled. Products obtained: 7.6 grams chloroform washed, s. g. $1.48 ; 700 \mathrm{cc}$. diluted mixed alcohols (distillate E).

6. Materials used: Ioo grams bleach, 35 per cent.; enough water to make $300 \mathrm{cc}$; $20 \mathrm{cc}$, ethyl alcohol, 94 per cent.; 700 cc. distillate $\mathrm{E}$; mixed at $20^{\circ} \mathrm{C}$. and distilled. Products obtained: 7.8 grams chloroform washed, s. g. $1.48 ; 700 \mathrm{cc}$. diluted mixed alcohols (distillate $F$ ).

\begin{tabular}{|c|c|c|c|}
\hline \multirow{2}{*}{$\begin{array}{l}\text { Number of } \\
\text { experiment. }\end{array}$} & \multirow{2}{*}{$\begin{array}{l}\text { Bleach, } 35 \text { per } \\
\text { cent., used. } \\
\text { Grams. }\end{array}$} & \multicolumn{2}{|c|}{$\begin{array}{c}\text { Chloroform washed, s. \&. 1.48, } \\
\text { obtained in }\end{array}$} \\
\hline & & Series 1 . & Series $t$ \\
\hline 1 & 100 & 1.2 & 1.2 \\
\hline 2 & 100 & 3.6 & 3.7 \\
\hline 3 & 100 & 5.4 & 5.2 \\
\hline 4 & 100 & 7.5 & 7.2 \\
\hline 5 & 100 & 6.7 & 7.6 \\
\hline 6 & 100 & 9.0 & 7.8 \\
\hline
\end{tabular}

Conclusions from Series F.-Comparing experiments Series D and F, it is proven that the presence of large amounts of methyl alcohol (free of acetone),

1 Address read at the Annal Meeting of the American institute of Chemical Jingincers, in Washington, D. C., Jyecember, 1911. 